\title{
A cardioembolic stroke
}

\author{
N. Benyounes ${ }^{1 *}$, R. Blanc ${ }^{2}$, S. Welschbillig ${ }^{3}$, M. Obadia ${ }^{4}$, G. Chevalier ${ }^{1}$, A. Cohen ${ }^{5}$ \\ ${ }^{1}$ Cardiology Unit, Fondation Ophtalmologique Adolphe de Rothschild, Paris, France \\ ${ }^{2}$ The Department of Interventional Neuroradiology, Fondation Ophtalmologique Adolphe de Rothschild, Paris, France \\ ${ }^{3}$ Intensive Care Unit, Fondation Ophtalmologique Adolphe de Rothschild, Paris, France \\ ${ }^{4}$ The Department of Neurology, Fondation Ophtalmologique Adolphe de Rothschild, Paris, France \\ ${ }^{5}$ The Department of Cardiology, Hospital Saint Antoine, Paris, France \\ Email: ${ }^{\text {nbenyounes@fo-rothschild.fr }}$
}

Received 26 November 2013; revised 28 December 2013; accepted 12 January 2014

Copyright (c) 2014 N. Benyounes et al. This is an open access article distributed under the Creative Commons Attribution License, which permits unrestricted use, distribution, and reproduction in any medium, provided the original work is properly cited. In accordance of the Creative Commons Attribution License all Copyrights (c) 2014 are reserved for SCIRP and the owner of the intellectual property N. Benyounes et al. All Copyright (c) 2014 are guarded by law and by SCIRP as a guardian.

\section{ABSTRACT}

A 76-year-old woman with unspecified congenital heart disease was admitted on April $25^{\text {th }}$ for TIA. She had a possible history of atrial fibrillation. A slight fever was noted on admission. Her ECG was abnormal, as well as her transthoracic echocardiography (TTE). Troponin I was slightly increased. On May $11^{\text {th }}$, a stroke occurred, in relation with an occlusion of the basilar artery. The patient was transferred to our institution for an emergency desobstruction. A dramatic improvement allowed her to be discharged to a rehabilitation center on May $18^{\text {th }}$. However, she was re-hospitalized on June $5^{\text {th }}$, due to sepsis and neurological worsening. MRI showed new ischemic brain lesions. Several episodes of paroxysmal atrial fibrillation were documented, as well as pulmonary hypertension. Effective heparin therapy was initiated and transesophageal echocardiography (TEE) was requested this time. It revealed a congenital valvular heart disease (a subaortic membrane), complicated by infective endocarditis. Despite a monitoring of aPTT, a fatal hemorrhagic shock occurred. We report this unfortunately remarkable case to address the following important points: 1) In the setting of a neurological event, abnormal ECG and/or abnormal TTE and/or Troponin I elevation may indicate a cardioembolic mechanism and therefore seek a cardiac source of embolism. 2) When TTE fails to identify a cardiac source of embolism, TEE should be performed, especially when a preexisting heart disease is suspected or known. 3) The multiplicity in space (infarcts in both the anterior and posterior circulation, or bilateral) and/or the multiplicity in time (infarcts of different

${ }^{*}$ Corresponding author. age) may indicate a cardioembolic stroke. 4) Congenital subaortic membrane predisposes to infective endocarditis. 5) When anticoagulant therapy is initiated on strong arguments in a septic patient (much discussed in infective endocarditis), aPTT monitoring alone may not be enough. An anti-Xa monitoring may be more appropriate.

\section{KEYWORDS}

Stroke; Echocardiography; Cardio-Embolic; Congenital Heart Disease; Infective Endocarditis

\section{INTRODUCTION}

Stroke is the third leading cause of death in several industrial countries. Embolism from a cardiac source accounts for approximately $15 \%$ to $30 \%$ of ischemic neurological events (stroke or TIA), and worsens the prognosis.

The most frequent cardiac sources of embolism are atrial fibrillation, left ventricular dysfunction and congestive heart failure, valvular heart disease (including infective endocarditis) and prosthetic valves, PFO (especially when associated with atrial septum aneurysm) and aortic arch atheroma and thrombosis.

Several neurological and cardiac features may suggest a cardioembolic origin. Hence, an accurate clinical evaluation in conjunction with the diagnostic imaging approach is particularly important, in order to provide the correct medical treatment for the patient with cardioembolic stroke [1].

\section{OBSERVATION}

A 76-year-old woman was admitted on April 25 ${ }^{\text {th }}, 2012$ 
to a neurovascular unit of a university-affiliated hospital for left facial paralysis and vertigo, lasting less than 24 hours. The MRI of her brain, including Flair DWI axial sequences and intracranial MR angiography was within normal, without evidence of stroke. The ECG was in sinus rhythm, with negative $\mathrm{T}$ waves in the lateral leads. Transthoracic echocardiography (TTE) on April $27^{\text {th }}$ showed apico-lateral and antero-septal hypokinesia. LVEF was $54 \%$. There was a slight dilatation of the aortic root $(42 \mathrm{~mm}$ at Valsalva sinuses and $45 \mathrm{~mm}$ at the tubular portion). A moderate aortic regurgitation was noticed. There was a slight elevation in serum Troponin I levels $(0.53 \mu \mathrm{g} / \mathrm{l}$ reference $<0.11)$ at admission. The maximal temperature during hospitalization was 37.9 degrees on April 30 ${ }^{\text {th }}$.

The patient had a history of congenital moderate aortic insufficiency and probably paroxysmal atrial fibrillation since she was receiving amiodarone and aspirin.

On May 11th, she experienced a new-onset of rightsided hemiparesis with dysarthria and nystagmus. Cerebral MRI showed at this time an ischemic stroke in the vertebrobasilar territory, in relation with an occlusion of the Basilar artery. Hence, the patient was immediately transferred to our Department of Interventional Neuroradiology for emergency mechanical recanalization of the occlusion. NIHSS score at admission was 4 . The diagnostic angiogram confirmed the occlusion of the Basilar artery (Figure 1, panel 1a) and a mechanical thrombectomy and stenting of the Basilar artery was performed. Despite a residual stenosis, a complete anterograde flow was noted on the final control cerebral angiogram (Figure 1, panel 1b). On May $14^{\text {th }}$, serum Troponin I was $<0.01$, NT-pro BNP (which elevation reflects elevated left ventricular filling pressures) was $323 \mathrm{pg} / \mathrm{ml}$ (normal for age), WBC count was $9600 / \mathrm{mm}^{3}$ and CRP was $18.2 \mathrm{mg} / \mathrm{l}$. Urine culture was positive for Escherichia coli $(10.000 .000 / \mathrm{ml})$.

The patient left for a rehabilitation center on May $18^{\text {th }}$. Her NIHSS was 2.

On June $3^{\text {rd }}$, false routes disorders and fever occurred, followed by respiratory distress requiring oxygen therapy. Probabilistic antibiotic therapy was started with Amoxicillin Clavulanate (1 g every 12 hours, intravenously).

On June $5^{\text {th }}$, a neurological deterioration was noted, in this setting of sepsis so the patient was again admitted to our neurovascular unit. Cerebral MRI showed new ischemic lesions in the vertebro-basilar territory. The rapid neurological deterioration on the same day required mechanical ventilation. On June $6^{\text {th }}$, serum Troponin I was $<$ $0.1 \mu \mathrm{g} / \mathrm{l}$ (reference $<0.5$ ) and BNP was $406 \mathrm{pg} / \mathrm{ml}$ (gray zone).

TTE on June $7^{\text {th }}$ confirmed the slight dilatation of the aortic root (42.5 mm at Valsalva sinuses). A subvalvular aortic membrane was suspected. The known moderate aortic regurgitation was visualized and a pulmonary hypertension was present (systolic PAP of $73 \mathrm{mmHg}$ ). NT-pro BNP reached $4603 \mathrm{pg} / \mathrm{ml}$. WBC count was $10000 / \mathrm{mm}^{3}$, fibrinogen reached $10.45 \mathrm{~g} / \mathrm{l}$ and CRP 348 $\mathrm{mg} / \mathrm{l}$ on the same day.

On June $8^{\text {th }}$, a paroxysmal atrial fibrillation occurred, poorly tolerated, requiring a first electrical cardioversion. NT-pro BNP reached $8427 \mathrm{pg} / \mathrm{ml}$. WBC count was $11800 / \mathrm{mm}^{3}$. Serum Troponin I levels remained within normal $(0.04 \mu \mathrm{g} / \mathrm{l}$ reference $<0.11)$. PCT reached 1.92 $\mathrm{ng} / \mathrm{ml}$. On June $9^{\text {th }}$, WBC was $17100 / \mathrm{mm}^{3}$.

Subcutaneous Enoxaparin $0.5 \mathrm{ml}$ twice a day has been initiated on June $7^{\text {th }}$, a pulmonary embolism being suspected (pulmonary hypertension on TTE), replaced by IV UFH on June $9^{\text {th }}$ (100 IU/2h, weight $50 \mathrm{Kg}$ ), given the documented atrial fibrillation. aPTT measures were correct except on June $15^{\text {th }}$ (Table 1). Antibiotics were maintained (Amoxicillin Clavulanate, 1 g every 8 hours). Diuretics were initiated intravenously. Noradrenalin has to be initiated on June $8^{\text {th }}$ and Dobutamin on June $9^{\text {th }}$.

A transesophageal echocardiography (TEE) on June $11^{\text {th }}$ demonstrated a subaortic membrane (Figure 1, panel 1c) without significant turbulence in the left ventricular outflow tract. A jet of moderate, grade 2, aortic insufficiency was present. An echogenic vegetating element $(6 \mathrm{~mm} \times 4 \mathrm{~mm})$ was attached to the ventricular side of the right coronary cusp of the aortic valve (Figure 1, panel 1d) and a thin mobile filamentous element was seen on the top of the membrane. Pulmonary hypertension regressed, with a systolic pulmonary pressure of 32 mmHg.

Twelve blood cultures were collected between June 11 and June 14 (three each day). On June $14^{\text {th }}$, antibiotics were modified: amoxicillin $1 \mathrm{~g}$ iv every 4 hours and gentamicin $240 \mathrm{mg}$ every day. All the blood cultures remained negative.

On June 16th, the patient required a first transfusion of 2 units of red cell components because of a fall in hemoglobin (Table 1). On June 19, abdominal CT scan showed a large hematoma of the left abdominal wall (15 $\times 15 \times 10 \mathrm{~cm}$ ). A second transfusion was performed.

Unfortunately, the patient died on June $22^{\text {nd }}$ from hemorrhagic shock.

\section{DISCUSSION: HOW TO UNCOIL THIS SKEIN?}

Most likely: infective endocarditis complicating a congenital heart disease from the beginning (the patient had a history of congenital aortic regurgitation), may be undiagnosed on the first TTE (April 27 $7^{\text {th }}$, 2013). Then, a TIA occurred (normal MR angiography), probably followed by a coronary embolism (abnormal ECG, abnormal left ventricular regional function, Troponin I eleva- 


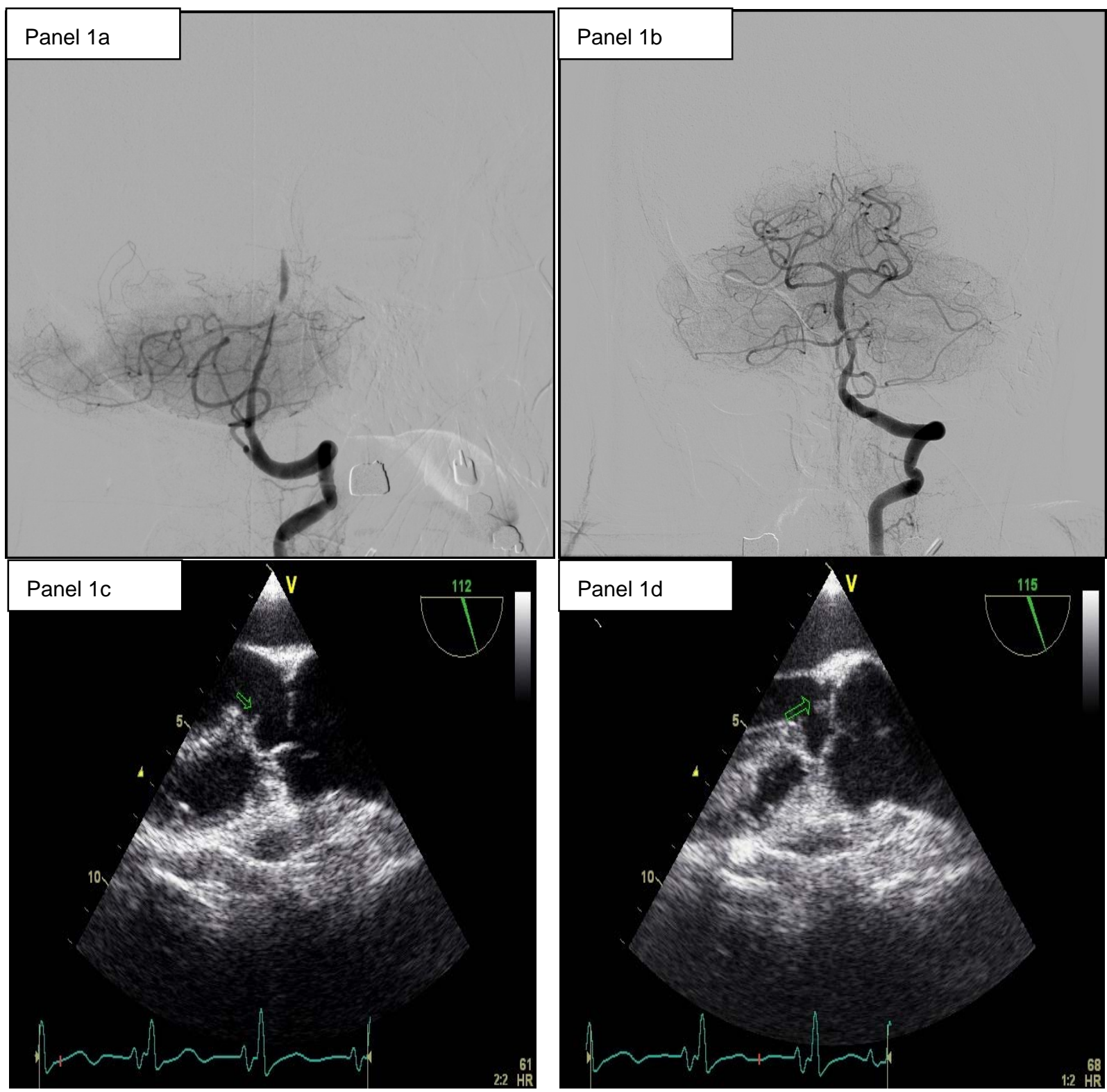

Figure 1. 1a: The angiogram showed an occlusion of the Basilar artery. 1b: Control cerebral angiogram after mechanical thrombectomy and stenting. Despite a residual stenosis, a complete anterograde flow is noted. 1c: A transesophageal echocardiography (TEE) showing a subaortic membrane. 1d: The same TEE shows aortic vegetations attached to the ventricular side of the non coronary cusp.

tion), then a first and a second stroke.

Three points are to discuss:

1. First: a first stroke of undetermined etiology in an elderly patient with a known or suspected congenital heart disease, especially in the presence of ECG and TTE abnormalities, and Troponin I elevation: could one prevent recurrent stroke?

2. Second: cerebral embolism complicating an infective endocarditis. An endovascular treatment is possible.

3. Third: anticoagulation in infective endocarditis. It is only useful to prevent recurrent arterial embolisms when other embolic risk factors are associated to infective en- docarditis [2]. What are the precautions for use?

Point 1: For the European Society Of cardiology, TTE and TEE are recommended when symptoms potentially due to a suspected cardiac aetiology including syncope, TIA, and cerebrovascular events are present [1]. The French Society of Cardiology recommend TEE in patients with cerebral infarction of undetermined cause despite clinical, biological and cervical arteries examinations and in patients with suspected endocarditis or known mitral or aortic valvular heart disease (Class I recommandation) [3].

Our Patient was suspected to have a congenital valvu- 
Table 1. Heparin therapy.

\begin{tabular}{|c|c|c|c|c|c|}
\hline Date & Heparin & $\begin{array}{c}\text { aPTT } \\
\text { (x control) }\end{array}$ & $\mathrm{Hb}(\mathrm{g} / \mathrm{dl})$ & WBC count $\left(/ \mathrm{mm}^{3}\right)$ & $\begin{array}{c}\text { PCT } \\
(\mathrm{ng} / \mathrm{ml})\end{array}$ \\
\hline June 11 & $1000 \mathrm{IU} / \mathrm{h}$ & & 11.5 & 17500 & \\
\hline June 12 & $1000 \mathrm{IU} / \mathrm{h}$ & & 10.6 & 15500 & \\
\hline June 13 & $1000 \mathrm{IU} / \mathrm{h}$ & & 9.6 & 24400 & \\
\hline June 14 & $1000 \mathrm{IU} / \mathrm{h}$ & & 9.1 & 27700 & 3.98 \\
\hline June 15 & $1000 \mathrm{IU} / \mathrm{h}$ & 4.13 & 8.7 & 19800 & 1.39 \\
\hline June 16 & $1000 \mathrm{IU} / \mathrm{h}$ & 2.75 & $\begin{array}{c}8.1 \\
\text { Transfusion }\end{array}$ & 15100 & 1.2 \\
\hline June 17 & $1000 \mathrm{IU} / \mathrm{h}$ & 2.57 & 11.1 & 14100 & 0.45 \\
\hline June 18 & $1000 \mathrm{IU} / \mathrm{h}$ & 2.78 & 11.1 & 15600 & \\
\hline June 19 & $1000 \mathrm{IU} / \mathrm{h}$ & & 10.0 & 18700 & 0.21 \\
\hline June 20 & 0 & 1.34 & 10 & 37800 & 0.16 \\
\hline
\end{tabular}

lar heart disease, had evidence of left ventricular damage and had a cerebral infarction of undetermined cause at her first admission for stroke. Despite this, she did not undergo TEE. If endocarditis was already present in April, TEE would probably have shown the vegetations. Subaortic membrane, which is a predisposing condition for endocarditis, would also have been visualized.

Subaortic membrane is a congenital heart disease, predisposing to infective endocarditis. The infection often involves the aortic valve and left ventricular outflow tract, and much more rarely the membrane itself [4]. In our patient, the infection has affected the aortic valve and the membrane. It is possible that the aortic valve is normal at birth in patients with subaortic membrane. However, the obstruction in the left ventricular outflow tract causes over time an impairment of the valve, which becomes more susceptible to infection. Our patient had a type II subaortic stenosis as angiographically described precedently [5]. That is a fibromuscular stenosis which may be associated with muscular hypertrophy and narrowing of the outflow tract. The membrane appears lower in the outflow tract than in patients with type I stenosis, usually involving the anterior leaflet of the mitral valve. In the majority of cases, the mitral valve appears to move normally, and the incompetence and massive septal hypertrophy seen with muscular obstruction are not seen. The severity of involvement varies but always had a characteristic appearance.

Morbidity and mortality associated with infectious endocarditis are very high.

Neurological complications of left sided infective endocarditis are very common. They include mycotic aneurysms, intracerebral abscess, intra-cerebral haemorrhage, meningitis and ischemic strokes [6]. These complications occur in more than half of the patients and are associated with high mortality. In-hospital mortality in infective endocarditis is reported to be as high as $20 \%$ [7].

An early diagnosis of the infective endocarditis and an appropriate identification of at risk patients on clinical, biological and echocardiographic variables are mandatory to improve patients' prognosis. In our patient, there was a delay in diagnosis.

Point 2: Mechanical thrombectomy has been performed in our patient before infective endocarditis diagnosis, allowing a desobstruction of the vertebrobasilar trunk and a clinical improvement.

Such treatment has been reported $[8,9]$ and may be better than thrombolysis in this setting [10].

Symptomatic and asymptomatic cerebral embolisms complicating infective endocarditis are frequent (in 43\% of patients in a series of 58 patients by diffusionweighted MRI) [11].

Usually, early surgical treatment is discussed in patients with active infective endocarditis complicated by cerebral infarction [12].

In our case, the endocarditis was treated medically because of the importance of the cerebral damage.

Point 3: Finally, anticoagulation was started in our patient, despite the newly diagnosed endocarditis. This attitude is questionable. However, the practitioner took this decision because of patients' history of atrial fibrillation and episodes of paroxysmal AF during hospitalization.

It is difficult to make the link between the UFH therapy and the spontaneous hematoma of the left iliac fossa. However, biological inflammatory syndrome makes the adaptation of heparin difficult. In addition, apparent heparin resistance due to increased factor VIII levels in an elderly male with infective endocarditis has been reported [13], pointing to the necessity of monitoring UFH intravenous therapy by anti-Xa assay (antithrombotic 
effect) and not aPTT levels (anticoagulant effect).

\section{CONCLUSIONS}

Stroke is the third leading cause of death in industrial countries and cardiogenic embolism accounts for $15 \%$ to $30 \%$ of ischemic strokes.

Cardiac sources of embolism have to be carefully sought and echocardiography (TTE and TEE) is the main diagnostic tool.

The most frequent cardiac sources of embolism are atrial fibrillation, left ventricular dysfunction and congestive heart failure, valvular heart disease (including infective endocarditis) and prosthetic valves, PFO (especially when associated with atrial septum aneurysm) and aortic arch atheroma and thrombosis.

Infective endocarditis is a life-threatening condition, with high in-hospital mortality, up to $20 \%$. Embolic events, both symptomatic and asymptomatic, occur in up to half of all the patients.

When a cerebral embolic infarction occurs in this setting, surgical treatment of the endocarditis has to be discussed. Mechanical thrombectomy of intracranial arteries is currently possible, and may be more appropriate than thrombolysis.

Finally, a major caution is needed when UFH treatment is needed in these patients, and the best monitoring is obtained using anti-Xa essay.

\section{ACKNOWLEDGMENTS}

The authors wish to thank Vanessa Badja for bibliographical assistance.

\section{DISCLOSURE OF INTEREST}

The authors declare that they have no conflicts of interest concerning this article.

\section{REFERENCES}

[1] Pepi, M., Evangelista, A., Nihoyannopoulos, P., Flachskampf, F.A., Athanassopoulos, G., Colonna, P., Habib, G., Ringelstein, E.B., Sicari, R., Zamorano, J.L., Sitges, M., Caso, P. and European Association of Echocariography (2010) Recommendations for echocardiography use in the diagnosis and management of cardiac sources of embolism: European association of echocardiography (EAE) (a registered branch of the ESC). European Journal of Echocardiography, 11, 461-476. http://dx.doi.org/10.1093/ejechocard/jeq045

[2] Whitlock, R.P., Sun, J.C., Fremes, S.E., Rubens, F.D., Teoh, K.H. and American College of Chest Physicians (2012) Antithrombotic and thrombolytic therapy for valvular disease: Antithrombotic therapy and prevention of thrombosis, 9th ed: American College of chest physicians evidence-based clinical practice guidelines. Chest, 141,
e576S-600S.

http://dx.doi.org/10.1378/chest.11-2305

[3] Cohen, A., Abergel, E., Blanchard, B., Chauvel, C., Habib, G., Hagege, A., Isnard, R., Lardoux, H., Roudaut, R. and Wolf, J.E. (2003) Recommendations of the French society of cardiology concerning indications for doppler echocardiography. Archives des Maladies du Coeur et des Vaisseaux, 96, 223-263.

[4] Pentousis, D., Cooper, J.P. and Rae, A.P. (1996) Bacterial endocarditis involving a subaortic membrane. Heart, 76, 370-371. http://dx.doi.org/10.1136/hrt.76.4.370

[5] Kelly, D.T., Wulfsberg, E. and Rowe, R.D. (1972) Discrete subaortic stenosis. Circulation, 46, 309-322. http://dx.doi.org/10.1161/01.CIR.46.2.309

[6] Tisdell, J., Smith, T.W. and Muehlschlegel, S. (2012) Multiple septic brain emboli in infectious endocarditis. Archives of Neurology, 69, 1206-1207. http://dx.doi.org/10.1001/archneurol.2011.3563

[7] Thuny, F., Grisoli, D., Collart, F., Habib, G. and Raoult, D. (2012) Management of infective endocarditis: Challenges and perspectives. Lancet, 379, 965-975. http://dx.doi.org/10.1016/S0140-6736(11)60755-1

[8] Dababneh, H., Hedna, V.S., Ford, J., Taimeh, Z., Peters, K., Mocco, J. and Waters, M.F. (2012) Endovascular intervention for acute stroke due to infective endocarditis: Case report. Neurosurgical Focus, 32, E1. http://dx.doi.org/10.3171/2011.11.FOCUS11263

[9] Sukumaran, S., Jayadevan, E.R., Mandilya, A., Sreedharan, S.E., Harikrishnan, S., Radhakrishnan, N. and Sylaja, P.N. (2012) Successful mechanical thrombectomy of acute middle cerebral artery occlusion due to vegetation from infective endocarditis. Neurology India, 60, 239-240. http://dx.doi.org/10.4103/0028-3886.96424

[10] Ong, E., Mechtouff, L., Bernard, E., Cho, T.H., Diallo, L.L., Nighoghossian, N. and Derex, L. (2013) Thrombolysis for stroke caused by infective endocarditis: An illustrative case and review of the literature. Journal of Neurology, 260, 1339-1342. http://dx.doi.org/10.1007/s00415-012-6802-1

[11] Iung, B., Klein, I., Mourvillier, B., Olivot, J.M., Détaint, D., Longuet, P., Ruimy, R., Fourchy, D., Laurichesse, J.J., Laissy, J.P., Escoubet, B. and Duval, X. (2012) Respective effects of early cerebral and abdominal magnetic resonance imaging on clinical decisions in infective endocarditis. EHJ Cardiovascular Imaging, 13, 703-710. http://dx.doi.org/10.1093/ehjci/jes023

[12] Yoshioka, D., Sakaguchi, T., Yamauchi, T., Okazaki, S., Miyagawa, S., Nishi, H., Yoshikawa, Y., Fukushima, S., Saito, S. and Sawa, Y. (2012) Impact of early surgical treatment on postoperative neurologic outcome for active infective endocarditis complicated by cerebral infarction. The Annals of Thoracic Surgery, 94, 489-495. http://dx.doi.org/10.1016/j.athoracsur.2012.04.027

[13] Thota, R., Ganti, A.K. and Subbiah, S. (2012) Apparent heparin resistance in a patient with infective endocarditis secondary to elevated factor VIII levels. Journal of Thrombosis and Thrombolysis, 34, 132-134. http://dx.doi.org/10.1007/s11239-012-0692-z 